\title{
A CharT FOR THE SePARATION OF NATURAL AND SYNTHETIC DIAMONDS
}

\author{
By James E. Shigley, Emmanuel Fritsch, Ilene Reinitz, and Thomas M. Moses
}

A chart is provided that describes those gemological properties that are key to the separation of gem-quality yellow, blue, and near-colorless (to colorless) natural diamonds from synthetic diamonds. This format was designed to give jewelers and gemologists a ready reference to identify synthetic diamonds as they enter the jewelry trade. Magnification and luminescence are the most important testing techniques currently available to jewelers and gemologists. The most distinctive features of synthetic diamonds include color zoning, graining, metallic inclusions (often making the stone magnetic), and uneven ultraviolet fluorescence.

\section{ABOUT THE AUTHORS}

Dr. Shigley is director of GIA Research, Santa Monica, California; Dr. Fritsch is professor of physics at the Gemology Laboratory, Physics Department, University of Nantes, France. Dr. Reinitz is a research scientist, and Mr. Moses is vice president of Identification Services, in the GIA Germ Trade Laboratory, New York.

Acknowledgments: In addition to the many GIA contributors, the authors thank the following: Dr. Alan Collins of King's College, London; and Mr. Martin Cooper and Dr. Chris Welboum of the De Beers Research Centre, Maldenhead, England. Financial support for this chart came from De Beers.

Gems \& Gemology, Vol. 31, No. 4, 1995 , pp. 256-264

(9) 1996 Gemological Institute of America

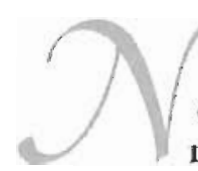

ow that small numbers of gem-quality synthetic diamonds have begun to appear in the jewelry industry, it has become critical that the professional jeweler/gemologist have the skills not only to quality grade a diamond, but also to identify that it is a natural, untreated stone. This article accompanies a chart that describes the distinctive gemological properties of natural as compared to synthetic gem diamonds (figure 1). In particular, the chart was designed to bring together in summary form those characteristics of gem-quality synthetic diamonds that will enable jewelers and gemologists to readily distinguish them from natural diamonds. This article describes the information contained in the chart, how it is organized, how it can be used in a standard gem identification procedure, and how the diagnostic gemological features can be resolved or recognized using standard gem-testing equipment. Some additional data, obtained through advanced techniques such as energy-dispersive X-ray fluorescence chemical analysis, infrared spectroscopy, and cathodoluminescence, are also cited because they provide useful information that the well-equipped gem-testing laboratory can use to support a conclusion. With this chart, jewelers and gemologists alike have the means to identify the variety of gem-quality synthetic diamonds available at this time (see Box A).

\section{BACKGROUND}

Over the past several years, various gemological researchers have published information on gem-quality synthetic diamonds and their practical gemological identification. Important articles include those by Crowningshield (1971), Koivula and Fryer (1984), Shigley et al. $(1986,1987,1993 a$, 1995), Ponahlo (1992), Rooney et al. (1993), Moses et al. (1993a), Scarratt et al. (1994), Kanda and Lawson (1995), and Sunagawa 


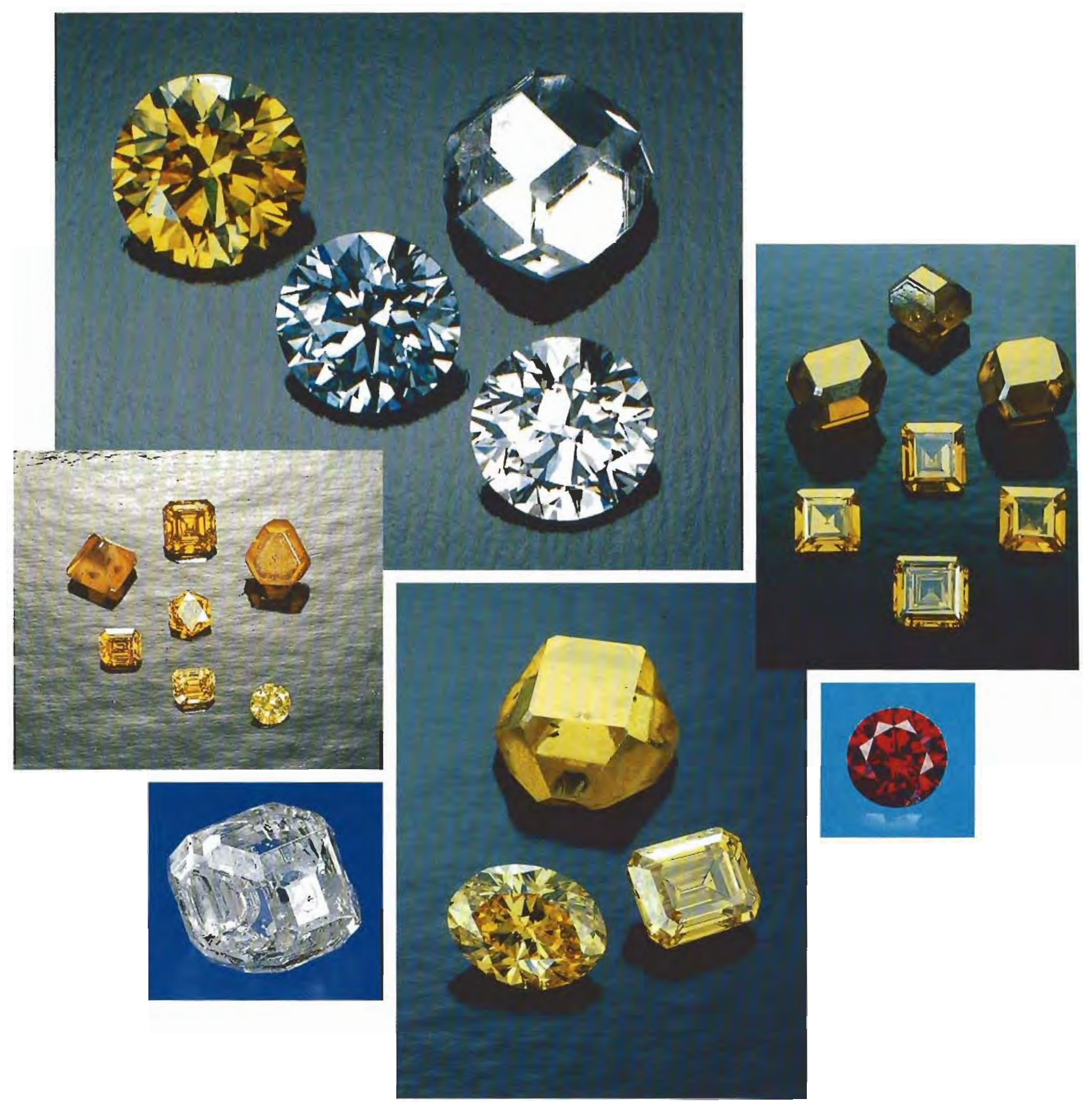

Figure 1. Shown here are some of the synthetic diamonds examined by GIA researchers to date (clockwise from top photo): (1) three faceted (0.39 ct yellow, $0.31 \mathrm{ct}$ grayish blue, and $0.30 \mathrm{ct}$ near-colorless) synthetic diamonds and one crystal (0.73 ct near-colorless) grown experimentally by General Electric; (2) three Sumitomo yellow crystals (top, 0.63-1.07 ct) and four yellow synthetic faceted stones $(0.16-0.24 \mathrm{ct}$ ); (3) a $0.14 \mathrm{ct}$ synthetic diamond with a dark red color caused by treatment; (4) De Beers experimental yellow synthetic diamonds-0.30 ct (left), $0.27 \mathrm{ct}$ (right), and a $1.03 \mathrm{ct}$ crystal (top); (5) a $0.42 \mathrm{ct}$ near-colorless crystal produced in Russia; (6) two yellow Russian as-grown crystals (left, $0.78 \mathrm{ct}$; right, $0.88 \mathrm{ct}$ ), plus three as-grown $(0.18-0.51 \mathrm{ct}$ ) and two treated $(0.14-0.21 \mathrm{ct}$ ) faceted synthetic diamonds. Photos are by, again clockwise from top. Tino Hammid (first two), Shane F. McClure, Tino Hammid, Shane F. McClure, and Robert Weldon. 


\section{Box A: A Practical Guide for Separating NATURAL FROM SyNTHETIC DiamondS}

Synthetic diamonds have a number of gemological properties by which they can be identified reliably. However, this requires that jewelers look at diamonds more carefully, and document more properties than they traditionally have documented. The following is a step-by-step procedure, to be used in conjunction with the information and illustrations on the chart, by which synthetic diamonds can be identified by any trained gemologist using standard gemological equipment.

\section{MAGNIFICATION}

The first step in grading, appraising, or purchasing a diamond is to examine the stone with magnification, preferably with a gemological microscope. This procedure, in which the observer determines such important information as the clarity and other grading parameters, is also critical to detemuining whether the diamond is natural or synthetic.

Careful observation of the inclusions present often reveals the identification of the diamond conclusively. For example, an included crystal of a transparent guest mineral such as garnet, enstatite, or diopside--or of another diamond-identifies the diamond as natural. Conversely, if you see a dark, opaque inclusion, you would want to look at it very carefully using such lighting methods as fiber-optic illumination to determine if its luster is reflective and metallic (figure A-1). If so, it might be a piece of metallic flux, in which case testing for magnetism (see below) would be sufficient to prove that it is a synthetic.

In situations where the diamond is of higher clarity and no diagnostic inclusions are present, close examination of growth features may aid in identification. "Hourglass" graining, which is usually visible through the pavilion, is related to the octahedral and cubic internal growth sectors of synthetic diamonds. Consequently, the presence of hourglass graining is proof that the diamond is synthetic. Any graining (colorless, colored, whitish, green, or even surface graining) following the octahedral planes throughout the stone would indicate that the diamond is natural. Likewise, phantom graining along the octahedral directions would also serve to identify a diamond as natural.

In a colored diamond, any color zoning observed can be useful for making the identification; examination with diffused transmitted light is very helpful in this regard. Natural diamonds may show planar bands of color or a roiled effect, but only synthetic diamonds would show pattems related to the intemal growth sectors.

\section{ULTRAVIOLET FLUORESCENCE}

If no diagnostic features are seen with magnification, or to confirm a preliminary identification made on the basis of internal features, you would look next at the reaction to long- and short-wave ultraviolet (UV) radiation. In most instances, there will be some distinguishing fluorescence features present. In the past, the fluorescence reactions of diamonds were not perceived as key identifying features by the jeweler or gemologist, who was solely concerned with grading concepts such as the strength and color of the reaction to long-wave UV radiation. For grading purposes, the diamond is placed table down under a long-wave UV light source in partial darkness. For identification purposes, it is preferable to view the stone from all directions, under both wavelengths of UV light, in total darkness. In the latter case, the pattern (or zoning) of the fluorescence is often more important than the fluorescence color.

A natural diamond typically fluoresces blue to long-wave UV (LWUV) radiation, with a weaker and usually yellow reaction to short-wave UV (SWUV). This fluorescence is usually evenly distributed, but it may be planar. Conversely, synthetic diamonds typically fluoresce yellow to yellowish green to both LWUV and SWUV, with the reaction often noticeably stronger to short-wave than long-wave. In addition, the internal growth sectors of a synthetic diamond generally produce a cross-shaped, octagonal (or similar geometric) pattern of fluorescence to either or both wavelengths.

In some cases, fluorescence may be stronger to LWUV than to SWUV, or the reaction to both wavelengths may be similar in strength, unlike the noticeable difference in intensity usually present in natural diamonds. Low magnification can be useful to observe any zoning of the fluorescence reaction. (An Optivisor is well-suited for this purpose; if a microscope is adapted for this use, precautions should be taken to shield the operator's eyes from the short-wave UV radiation.)

Ultraviolet fluorescence is a test commonly used by jewelers and gemologists, and simple observations such as these may identify the diamond conclusively. In addition, an entire parcel of stones can be tested at one time.

\section{SPECTROSCOPY}

To date, most of the gem-quality synthetic diamonds encountered in the trade have been yellow to brownish yellow in body color; they have been identified as synthetic during the testing procedure used to determine their "origin of color." Observation of the spectrumwith a prism or diffraction-grating (hand-held or deskmodel) spectroscope-is a routine test for colored diamonds. The spectra of most natural diamonds, whether of natural or treated color, differ from those seen in synthetic diamonds. The most common spectral features 
seen in natural diamonds are the "Cape" lines at 415 $\mathrm{nm}$ and at 452,465 , and $478 \mathrm{~nm}$. On the basis of the samples we have examined to date, we believe that the presence of a $415 \mathrm{~nm}$ line in a colorless to light yellow diamond can be considered proof that the stone is natural.

Treated-color natural diamonds may show additional absorptions at 496, 503, 595, or $637 \mathrm{~nm}$. Such spectral features suggest that the diamond is natural (even if the color is treated). Absence of the $415 \mathrm{~nm}$ line would not prove that the diamond is synthetic, but it would make it necessary to test the stone further.

Some synthetic diamonds show a number of absorption lines between 470 and $700 \mathrm{~nm}$ (see chart) which are due to the nickel used in the flux. Observation of several of these lines would indicate a synthetic. However, most colored synthetic diamonds are predominantly type $\mathrm{Ib}$, so no sharp absorption features are expected in the visible spectrum. Rarely, natural diamonds are type Ib or type IIa, and these are not expected to show spectral lines.

\section{MAGNETISM}

The metal fluxes used to help grow synthetic diamonds often leave metallic inclusions-from submicroscopic particles to eye-visible pieces-in the synthetic stone. Such inclusions are magnetic and may be attracted by a strong magnet. To detect this magnetism, the diamond can be suspended from a string and sheltered against air currents, while the magnet is placed close to the stone (but not touching it). Moving the magnet from side to side should induce a parallel motion in a synthetic diamond, but will cause no movement in a natural stone.

As mentioned above, observation of a dark inclusion with a metallic luster would lead you to perform this test, although finely dispersed flux that is not resolvable under magnification may also react to a magnet. Thus, a clear response of the diamond to the magnet proves that it is synthetic, but lack of a magnetic response only suggests that it is natural. In rare instances, a natural diamond may contain inclusions that cause the stone to be faintly attracted to a strong magnet, but such a diamond will undoubtedly have other properties that prove it to be natural.

\section{STRAIN}

Anomalous double refraction (ADR), commonly called "strain," is a characteristic of diamonds that normally goes unnoticed by the jeweler or gemologist, although it is well known to diamond manufacturers. It can be observed by holding the diamond from table to culet under a polariscope or between crossed polarizing filters attached to a gemological microscope. Although this is not a "stand-alone" test, it is particularly useful when the stone is free of inclusions, is of high color, or shows no "Cape" series in the spectroscope. Natural diamonds generally show banded, cross-hatched, or mottled strain

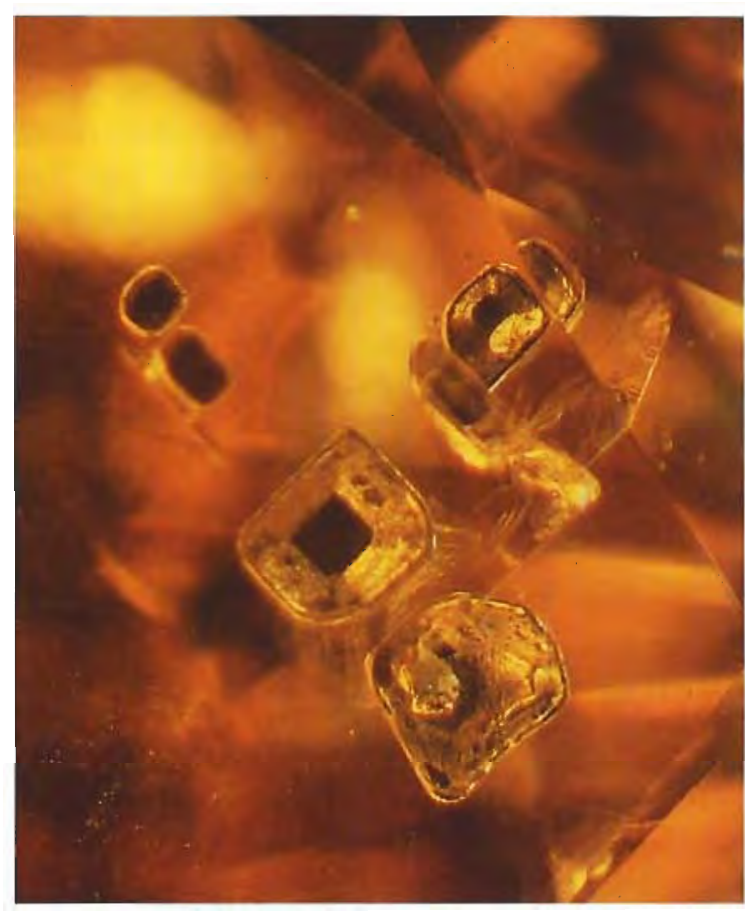

Figure A-1. A group of metallic inclusions is seen here under the table facet of a brownish yellow synthetic diamond. Although the square shape of the inclusions is somewhat unusual, their opaque appearance in transmitted light is very characteristic. Photomicrograph by John $I$. Koivula; magnified $25 x$

patterns and bright interference colors, whereas the strain present in synthetic diamonds shows a cross-like pattem in subdued colors, mainly black and gray.

\section{SUMMARY}

Whether the diamond is ultimately to be examined for grading or for its origin of color (procedures that differ considerably], you can determine the stone's natural or synthetic origin by using one or more of these basic gemological tests:

1. Examine the stone with magnification, looking for inclusions, color zoning, and graining.

2. Observe the UV fluorescence, especially with the stone in the face-up position, looking for both a fluorescence pattern and the relative strength of fluorescence to LWUV and SWUV.

3. Look at the spectrum with a hand-held or deskmodel spectroscope.

4. Check whether a suspected synthetic reacts to a strong magnet.

5. If necessary, observe the strain patterns/colors between crossed polarizers. 
(1995). Other articles, taken mainly from the gemological literature, are provided in the "Additional Reading" addendum to the "References" list. The purpose of all these articles has been to inform the jewelry trade (and, indirectly, the public at large) about synthetic gem diamonds from various manufacturers (in particular, experimental samples from General Electric and De Beers, and commercial material from Sumitomo and various Russian laboratories [again, see figure 1]]. The articles have also demonstrated how to identify those gemological characteristics that trained jewelers and gemologists can use to separate synthetic diamonds from their natural counterparts.

We believe that, to date, synthetic diamonds of a size and quality suitable for faceting have been grown only in limited numbers and have had little, if any, adverse impact on the jewelry industry. However, as the costs of production go down (with improvements in the technology of diamond synthesis), it is possible that such synthetics will be less rare in the future. The only synthetic diamonds encountered in the trade by the GLA Gem Trade Laboratory (GIA GTL) have been yellow (10 samples seen since 1987 with nine of these seen since 1993: see, e.g., Moses et al., 1993b; Kammerling et al., 1993, 1995b) or red (three samples seen, all with the color due to laboratory treatment; the first two are described in Moses et al., 1993a). A faceted $1.23 \mathrm{ct}$ brown-yellow synthetic diamond was examined by staff members of the Hoge Raad voor Diamant (HRD) certificates laboratory in
Antwerp (van Royen, 1994, p. 44). A 2.32 ct brownyellow brilliant-cut pear-shaped synthetic diamond was reported by the Gemmological Association of Great Britain Gem Testing Laboratory in London (Emms, 1994). Synthetic yellow diamonds from Russia have also been examined by gemologists in Germany (Henn and Bank, 1993), Thailand (Scarratt et al., 1994), and Italy (Sosso, 1995). The largest faceted synthetic diamond known to date is a $5.47 \mathrm{ct}$ brownish yellow stone (cut as a round brilliant) that was identified in early 1995 by staff members of GIA GTL. Despite the limited numbers of synthetic diamonds seen, the fear that they will enter the marketplace and will not be readily identifiable continues to haunt the trade (see, e.g., Costan, 1993; Nassau, 1993; "Chatham to sell 'created' diamonds," 1993; Helmer, 1994; Howard, 1995).

Most synthetic diamonds are brownish yellow to yellow, but blue and near-colorless crystals have also been grown in limited numbers, thus far primarily for experimental purposes. In all colors, samples suitable in size and quality for jewelry use have been faceted.

According to the research work published to date, those synthetic diamonds available thus far have several distinctive gemological properties that allow for their identification using readily available gem-testing techniques. For both as-grown and laboratory-treated colored synthetic diamonds (which tend to have saturated hues), we have found that the most diagnostic gemological properties are certain patterns of uneven color; uneven yellow to yellowish

Figure 2. Natural diamonds, like the $0.69 \mathrm{ct}$ near-colorless stone shown here on the left, typically fluoresce a relatively even blue to long-wave UV radiation. In contrast, synthetic diamonds, like this $0.13 \mathrm{ct}$ yellow synthetic on the right, typically fluoresce yellowish green to short-wave UV radiation, with an uneven (cross-like) pattern (the blue color at the lower right is merely a reflection of the UV lamp). Photomicrographs by John I. Koivula; magnified $5 \times$ (left) and $15 \times$ (right).
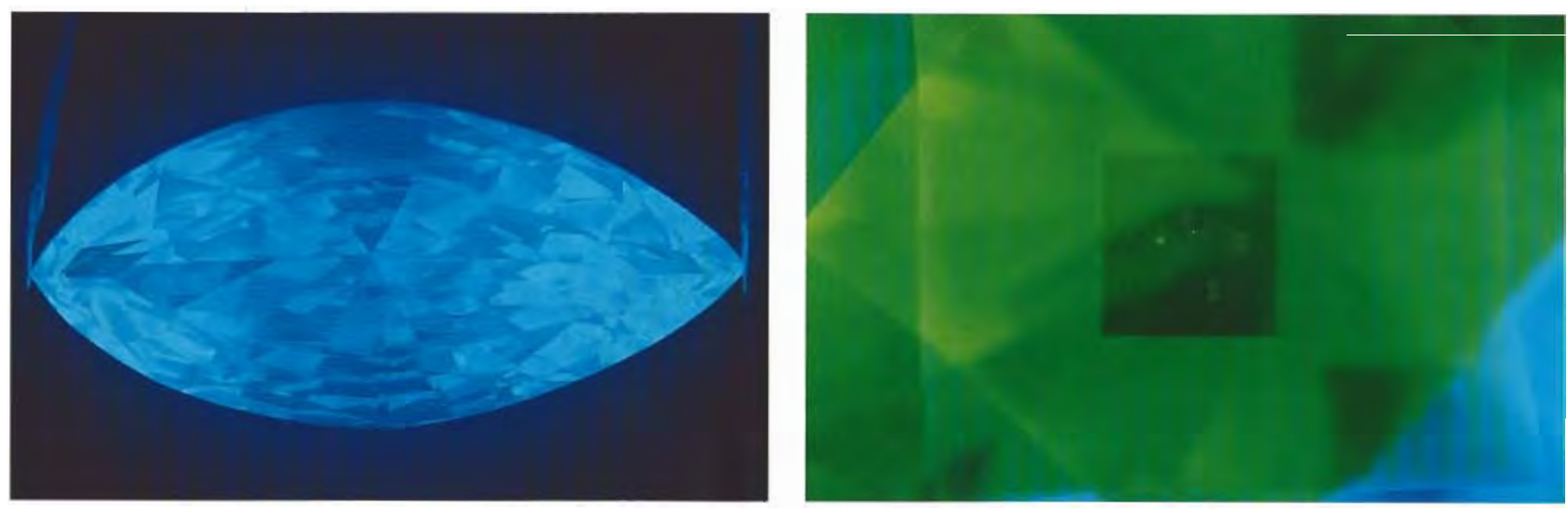
green ultraviolet (UV) fluorescence (figure 2), which is often stronger to short-wave (SWUV) than long-wave (LWUV) ultraviolet radiation; and certain graining patterns, as well as the presence of metallic flux inclusions. For near-colorless to colorless synthetic diamonds, the diagnostic properties are certain patterns of uneven UV fluorescence (so far, always stronger to SWUV), persistent phosphorescence, and metallic flux inclusions.

The zonation of color, UV fluorescence, and graining that is often so prominent in synthetic diamonds results from their internal structure, which contains octahedral, cubic, and sometimes additional growth sectors. Chemical impurities trapped from the laboratory growth environment are concentrated either along the boundaries between internal growth sectors, or in one sector and not in adjacent ones, in the synthetic diamond crystal (see Kanda and Lawson, 1995). The distinctive features of as-grown synthetic diamonds result from those conditions of diamond formation in the laboratory that differ from those in the earth (mostly in that diamonds are grown in a silicate solution in nature and a metallic solution in a laboratory; see Sunagawa, 1984, 1995).

The color of brownish yellow synthetic diamonds can be altered to either pink to red, or yellow to greenish yellow, by treatment processes such as irradiation followed by heating (Moses et al., 1993a), or heating at high pressure (Shigley et al., 1993a), respectively. These treatment processes will also alter gemological features such as UV fluorescence and absorption bands seen with a hand spectroscope (see italicized text on chart). Nevertheless, a treated synthetic diamond is no more difficult to detect than its untreated synthetic counterpart.

Although there are many similarities in gemological properties among synthetic diamonds from various manufacturers, and among those treated by different processes, there are also some differences. It is because of this that we decided to bring together in chart form those features that we currently know to be useful in the identification of synthetic diamonds.

\section{CONTENTS OF THE CHART}

The chart presents information on synthetic (both asgrown and laboratory-treated) diamonds and their natural counterparts in a vertical format organized by three general color groups: yellow, colorless to nearcolorless, and blue. For each general color group, we have summarized only the most useful gemological properties. For the most part, we chose to restrict

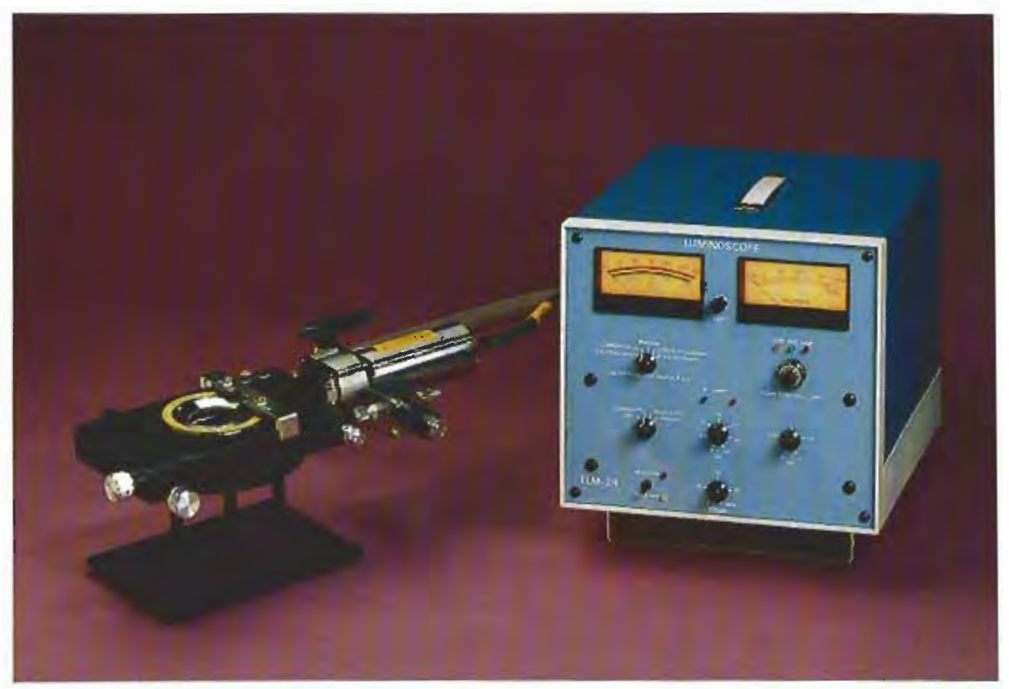

Figute 3. The Luminoscope, mantfactured by Premier American Technologies Corp., consists of two parts: On the left is the vacuum chamber and electron "gun," and on the right is the power supply and control tmit. Diamonds will emit visible cathodoluminescence, when they are bombarded by the electron beam in the vacuum chamber. Photo courtesy of Premier American Technologies Corp., Bellefonte, Pennsylvania.

information to properties of faceted natural or synthetic diamonds that could be documented readily by gemologists, although some other features such as crystal size and shape are included. Sunagawa (1995) provides a comprehensive discussion of the differences in morphology, surface features, and internal characteristics of rough natural and synthetic diamond crystals.

Some infomation derived from three other identification techniques-cathodoluminescence, energydispersive X-ray fluorescence (EDXRF) chemical analysis, and infrared spectroscopy - is also included on the chart. We believe that cathodoluminescence (luminescence generated by exposure of a material to a beam of electrons in an evacuated chamber), in particular, will soon become a more standard technique for testing diamonds in gemological laboratories (see Ponahlo, 1992, and photographs of cathodoluminescence in Shigley et al., 1987, 1993a). A relatively simple unit (known as a Luminoscope), which is capable of generating cathodoluminescence in diamonds and other gemstones, can be purchased for about US $\$ 20,000$ (figure 3). It consists of a sample chamber (from which the air can be evacuated, and which can 

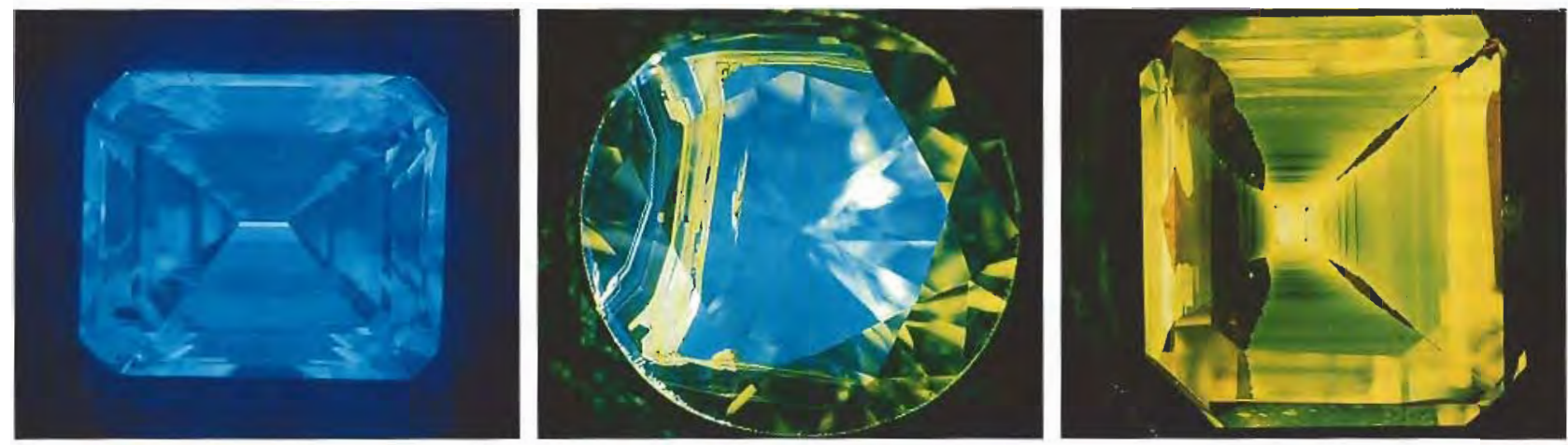

Figure 4. The natural diamond on the far left shows the relatively even blue cathodoluminescence typical of natural diamonds. However, some natural diamonds (center) exhibit a cathodoluminescence pattern that reflects their complex growth history. Nevertheless, these patterns are distinctly different from the green-to-yellow, cross-shaped cathodoluminescence pattern typically seen in synthetic diamonds (here, a crystal grown experimentally by De Beers). Photo on the left is by Maha DeMaggio (magnified 5x); center and right photos are by Michael Growder, De Beers Research Centre, Maidenhead, UK (magnified 6x and 2x, respectively).

be mounted on a microscope stage, if desired) with a viewing port, a "gun" that emits an electron beam, and the associated power supply. Our observations indicate that no diamond, natural or synthetic, is inert to cathodoluminescence (which is not the case with UV fluorescence). In addition, although the colors of luminescence generated by UV fluorescence and cathodoluminescence may differ, the characteristic pattern of internal growth sectors in a synthetic diamond can often be seen more easily using cathodoluminescence (figure 4). In those cases where the UV fluorescence is weak or indistinct, in particular, we have found that the more intense cathodoluminescence will reveal the presence of different internal growth sectors in synthetic diamonds (see Shigley et al., 1987, 1993a and b; Ponalho, 1992).

In this chart, we also cite some EDXRF chemical analysis results. This method is routinely used at gem-testing laboratories to distinguish natural, treated, and synthetic gem materials. Our EDXRF data indicate that synthetic diamonds typically contain traces of the flux metals (such as iron or nickel) from which they are grown (see, e.g., the EDXRF spectrum in Moses et al., 1993a, p. 185, and the data in Shigley et al., 1993a, p. 234, which indicate the presence of Fe and $\mathrm{Ni}$ in both as-grown and treated Russian synthetic diamonds). They may also contain elements such as aluminum or titanium that were added to the experimental system to remove nitrogen from the growing diamond crystal. Natural diamonds generally do not have trace impurities that can be detected by EDXRF (which cannot detect any of the low-atomic- number elements-such as carbon, nitrogen, or boron-typical of the major- and trace-element chemistry of natural diamond). On rare occasions, natural diamonds with mineral inclusions (such as gamet) may exhibit evidence of trace amounts of $\mathrm{Si}, \mathrm{Al}, \mathrm{Fe}$, $\mathrm{Mg}$, or Ti. Diamonds polished on an iron scaife may exhibit features consistent with Fe contamination.

Finally, we have included information that refers to diamond type (e.g., Ia, Ib, IIa, IIb), a traditional scheme used to classify all diamonds on the basis of their nitrogen and boron contents by means of infrared spectroscopy (for a good, concise discussion of diamond type, see Fritsch and Scarratt, 1992, pp. $38-39$. This classification of diamond is important because the type categories can be related to the gemological properties that diamonds exhibit. Asgrown synthetic yellow diamonds are type $\mathrm{Ib}$, a type that is very rare in nature; those that are treated at high pressure or that are irradiated and heat treated can be predominantly type IaA. Blue synthetic diamonds are type $\Pi b$ (as are most natural blues), whereas the near-colorless to colorless synthetics studied to date are usually type Ila. The type categories of corresponding colors of natural diamonds are also listed on the chart. It is important to note, however, that natural diamonds referred to as type $\mathrm{Ib}$, unlike synthetics, are rarely "pure" and usually contain some type Ia nitrogen.

Details of how these gemological properties were documented in both synthetic and natural diamonds are briefly presented in the "Key to Information" section at the bottom of the chart. 
Note that the chart does not present information on natural diamonds that might have a synthetic diamond coating placed on them to change their color or possibly their weight. In the course of our research, we arranged to have three natural type Ia colorless diamonds coated with a layer of blue, type $\Pi b$ synthetic diamond (Fritsch, 1991; Fritsch and Phelps, 1993). These three stones could be readily recognized by the uneven deposition of the synthetic diamond coating, resulting in irregularities in blue coloration (especially along facet junctions), as well as by distinctive features in their visible and infrared absorption spectra. To date, we have neither encountered nor heard of any situations where a synthetic diamond coating has been applied to a natural diamond primarily to change its weight or color.

\section{HOW THE INFORMATION IS ORGANIZED}

Within each column, we present in summary form only what we believe to be the most commonly seen gemological properties. We should emphasize that not all of these diagnostic features are likely to be found in each synthetic diamond. However, all synthetic diamonds we have examined to date display one or more of these features. As stated earlier, the most useful diagnostic properties include such features as color zoning, graining, metallic inclusions (microscopic and submicroscopic), usually causing the synthetic diamond to be attracted to a strong magnet (e.g., the neodymiun-iron-boron magnet "wand" developed by Alan Hodgkinson, described in Kammerling et al., 1995a), and uneven luminescence to both UV and electron radiation. Synthetic diamonds of a particular color have many similar gemological properties, although-as noted above--some differences may exist between samples from various manufacturers. Among natural diamonds, however, the variation in gemological properties can be much greater because of differences in both growth history and impurity contents in crystals from one locality to the next. Thus, there is a greater possibility for exceptions to the information on natural diamonds presented in the chart than to that given for synthetic diamonds.

The chart also includes a number of photographs and photomicrographs. These pictures were selected to illustrate visual features of synthetic and natural diamonds that have the greatest diagnostic value for identification purposes. The photographs are referenced by number (FIG $=$ figure) in the relevant portions of the chart.

\section{HOW THIS INFORMATION WAS ACQUIRED}

Most of the information presented in this chart is based on data collected by GIA researchers over the past eight years on approximately 120 synthetic diamonds. Information on natural diamonds comes from our documentation of the gemological properties of several thousand diamonds. Information on natural and synthetic diamonds reported by other researchers was compared with our data to confirm the information shown on the chart.

\section{CONCLUSION}

The accompanying chart summarizes the key characteristics of synthetic and natural diamonds, emphasizing the information that can be obtained by standard gem-testing methods, such as magnification, ultraviolet fluorescence, and optical absorption spectra. Synthetic diamonds currently being marketed can be identified positively and reliably on the basis of the information presented in this chart.

The chart also provides information derived from more advanced testing methods, such as cathodoluminescence, EDXRF chemical analysis, and infrared spectroscopy, where this information can provide confirmation of natural or synthetic origin.

\section{REFERENCES}

Chatham to sell "created" diamonds (1993). New York Diamonds, No. 22, Autumn, pp. 44, 46 .

Costan J. (1993) Slow start for Chatham diamonds. Diamond International, No. 26, November/December, pp. 71-72, 74.

Crowningshield R. (1971) General Electric's cuttable synthetic diamonds. Gems (t) Gemology, Vol. 13, No. 10, pp. 302-314.

Emms E.C. (1994) Synthetic surprises. Retail Jeweler, Vol. 31, No. 834 (November 3), pp. 8-9.

Fritsch E. (1991) Gemological applications of synthetic diamond and diamond-like carbon products grown using the low-pressure deposition technique. In A.S. Keller, Ed., Proceedings of

the International Gemological Symposium, Gemological Institute of America, Santa Monica, CA, p. 44.

Fritsch E., Scarratt K. (1992) Natural-color nonconductive gray-toblue diamonds. Gems e) Gemology, Vol. 28, No. 1, pp. 35-42.

Fritsch E., Phelps A.W. (1993) Type Ib diamond thin films deposited onto near-colorless gem diamonds. Diamond and Related Materials, Vol. 2, pp. $70-74$.

Helmer J. (1994) Synthetics-dilemma for Russia. Diamond International, No. 28, March/April, pp. 55-56.

Henn U., Bank H. (1993) Gemmologische Kurzinformationen. Zeitschrift für Deutschen Gemmologischen Gesellschaft, Vol. 
42, No. $2 / 3$, p. 66

Howard T. (1995) Much ado about man-made diamonds. American Jewelry Manufacturer, Vol. 40, No. 9 (Scptember), pp. 22, 24, I16.

Kammerling R.C., Moses T., Fritsch E. (1993) Gem trade lab notes: Faceted yellow synthetic diamond. Gems et Gemology, Vol. 29 , No. 4, p. 280.

Kammerling R.C., Koivula J.I., Fritsch E. (1995a) Gem news: New magnet for gem testing. Gems e) Gemology, Vol. 31, No. 1, p. 69.

Kammerling R.C., Reinitz I.R., Fritsch E. (1995b) Gem trade lab notes: Synthetic diamond suite. Gems et) Gemology, Vol. 31, No. 2, pp. 122-123.

Kanda H., Lawson S.C. (1995) Growth temperature effects of impurities in HP/HT diamonds. International Diamond Review, No. 2, pp. 56-61.

Koivulal J.I., Fryer C.W. (1984) Identifying gem-culality synthetic diamonds: An update. Gems Gemology, Vol. 20, No. 3, pp. $146-158$.

Moses T.M., Reinitz I., Fritsch E., Shigley J.E. (1993a) Two treatedcolor synthetic red diamonds seen in the trade. Gems et) Gemology, Vol. 29, No. 3, pp. 182-190.

Moses T., Kammerling R.C., Fritsch E. (1993b) Gem trade lab notes: Synthetic yellow diamond crystal. Gems es) Gemology, Vol. 29, No. 3, p. 200.

Nassau K. (1993) Are synthetic diamonds from Russia at threat? Rapaport Diamond Report, Vol. I6, No. 35 (November 5), pp. $29,31-32$

Ponalilo J. (1992) Cathodoluminescence (CL) and CL spectra of De Beers' experimental synthetic diamonds. Journal of Gemmology, Vol. 23, No. 1, pp. 3-17.

Rooney M-L.T., Welbourn C.M., Shigley J.E., Fritsch E., Reinitz I.
(1993) De Beers near colorless-to-blue experimental gem-quality synthetic diamonds. Gems 4) Gemology, Vol. 29, No. 1, pp. 38-45.

Scarratt K., Du Toit G., Sersen W. (1994) Russian synthetics examined. Diamond International, No. 28, March/April, pp. 45-52.

Shigley J.E., Fritsch E., Stockton C.M., Koivula J.I., Fryer C.W., Kane R.E. (1986) The gemological properties of the Sumitomo gem-(puality synthetic yellow diamonds. Gems e) Gemology, Vol. 22, No. 4, pp. 192-208.

Shigley J.E., Fritsch E., Stockton C.M., Koivula J.l., Fryer C.W. Kane R.E., Hargett D.R., Welch C.W. (1987) Gemological properties of the De Beers gem-quality synthetic diamonds. Gems e.) Gemology, Vol. 23, No. 4, pp. 187-206.

Shigley J.E., Fritsch E., Koivula J.I., Sobolev N.V., Malinovsky I.Y., Pal'yanov Y. (1993a) The gemological properties of Russian gem-quality synthetic yellow diamonds. Gems e) Gemology, Vol. 29, No. 4, pp. 228-248.

Shigley J.E., Fritsch E., Rcinitz I. (1993b) Two near-colorless General Electric type-Ila synthetic cliamond crystals. Gems $\omega$ Gemology, Vol. 29, No. 3, pp. 191-197.

Shigley J.E., Fritsch E., Koivula J.I., Kammerling R.C. (1995) Identifying features of synthetic diamonds, Rapaport Diamond Report, Vol. 18, No. 20 (June 2), pp. 4-5 plus insert supplement.

Sosso F. (1995) Some observations on a gem-quality synthetic yellow diamond produced in the region of Vladimir (Russia). Journal of Gemmology, Vol. 24, No. 5, pp. 363-368.

Sunigawa I., Ed. (1984) Materials Science of the Eorth's Interior, Terra Scientific Publishing Co., Tokyo.

Sunagawa 1. (1995) The distinction of natural from synthetic diamond. Journal of Gemmology, Vol. 24, No. 7, pp. 485-499.

van Royen J. (1994) Fancy colour diamonds. Antwerp Facets, pp. 41-49.

\section{ADDITIONAL READING}

Collins A.T. (1991) Optical centres in synthetic diamonds-a review. In R. Messier, J.T. Glass, J.E. Butler, R. Roy, Eds., New Diamond Science and Technology, Materials Research Society, Pittsburgh, pp. 659-670.

Crowningshicld R. (1990) Gem trade lab notes: Diamond, fancy intense yellow. Gems e.) Gemology, Vol. 26, No. 4, pp. 295-296.

Field J.E. (1992) The Properties of Natural and Synthetio Diamonds. Academic Press, London.

Fritsch E., Shigley J.E. (1993) The separation of natural from synthetic gem-quality diamonds on the basis of crystal growth criteria. Journal of Crystal Growth, Vol. 128, pp. 425-428.

Fryer C.W. (1987) Gem tracle lab notes: Synthetic diamond. Gems et) Gemology, Vol. 23, No. 1, p. 44

Günther B. (1995) Synthetische Diamanten und Ihre Erkennung, Gold und Silber, No. 2, pp. 46-48.

Koivula J.l., Kammerling R.C. (1990) Gem news: De Beers announces world's largest synthetic diamond crystal. Gems $e$ ) Gemology, Vol. 26, No. 4, p. 300.

Koivula J.1., Kammerling R.C. (1991) Gem news: G.E. synthesizes large carbon-13 diamonds. Gems e) Genology, Vol. 27, No. 4, pp. 254-255.

Koivula J.I., Kammerling R.C. (1991) Gem news: Gem-quality synthetic diamonds from the USSR. Gems et) Gemology, Vol. 27, No. 1, p. 46.

Koivula J.I., Kammerling R.C., Fritsch E. (1992) Gem news: An update on diamond research. Gems e) Gemology, Vol. 28, No. 4, pp. 268-269.

Koivula J.l., Kammerling R.C., Fritsch E. (1993) Gem news: De Beers now marketing high-quality, high-pressure synthetic diamond products. Gems \&) Gemology, Vol. 29, No. 2, p. 130.

Koivula J.I.., Kammerling R.C., Fritsch E. (1993) Gem news: GIA says Russian gem-quality synthetic diamonds examined to date can be identified by standard tests. Gems \& Gemology,
Vol. 29, No. 3, pp. 207-208.

Koivula J.I., Kammerling R.C., Fritsch E. (1993) Gem news: Sumitomo Electric synthesizes high-purity diamonds. Gens $\left.e_{t}\right)$ Gemology, Vol. 29, No. 3, p. 208.

Liddicoat R.T. Jr. (1986) The ultimate synthetic: A jewelry-quality diamond. Gems et) Gemology, Vol. 22, No. 4, p. I91.

Nassau K. (1993) Five different kinds of synthetic diamond. Canadian Gemmologist, Vol. 14, No. 1, pp. 8-12.

Nassau K., Nassau J. (1978) The history and present status of synthetic diamond, Parts 1 and II. Lapidary Journal, Vol. 32, Nos, 1 and 2, pp. 76-96 and 490-508.

Recker K. (1984) Synthetische Diamanten. Zeitschrift der Deutschen Gemmologischen Gesellschaft, Vol. 33, No. 1/2, pp. 5-34.

Rossman G., Kirschvink J.L. (1984) Magnetic properties of gemquality synthetic diamonds. Gems et) Gemology, Vol. 20, No. 3, pp, 163-166.

Scarratt K. (1987) Notes from the laboratory-11. Journal of Gemmology, Vol. 20, No. 7/8, pp. 406-409.

Shigley J.E., Fritsch E., Stockton C.M., Koivula J.I., Frycr C.W., Kane R.E. (1987) Les diamants synthétiques Sumitomo. Revue de Gemmologie a.f.g., No. 92, pp. 10-I4.

Shigley J.E., Fritsch E., Reinitz I., Moon M. (1992) An update on Sumitomo gem-quality synthetic diamonds. Gems 4 ) Gemology, Vol. 28, No. 2, pp. 116-I22.

Shigley J.E., Fritsch E., Kammerling R.C., Koivula J.I., Moses T.M. (1993) Identifying gem-quality synthetic diamonds. Rapaport Dianiond Report, Vol. 16, No. 26 (August 6), pp. I0-13.

Shigley J.E., Fritsch E., Kammerling R.C., Moses T.M. (1993) Identifying faceted gem-quality synthetic diamonds. New York Diamonds, No. 22, Autumn, pp. 48-54.

Wakatsuki $M$. (1984) Synthesis rescarches of diamond. In I. Sunagawa, Ed., Materials Science of the Earth's Interior, Terra Scientific Publishing Co., Tokyo, pp. 35 I-374. 